\title{
PCM Thermal Control Unit for Portable Electronic Devices: Experimental and Numerical Studies
}

\author{
Esam M. Alawadhi and Cristina H. Amon, Fellow, IEEE
}

\begin{abstract}
This paper investigates the effectiveness of a thermal control unit (TCU) for portable electronic devices by performing experimental and numerical analyses. The TCU objective is to improve thermal management of electronic devices when their operating time is limited to a few hours. It is composed of an organic phase change material (PCM) and a thermal conductivity enhancer (TCE). To overcome the relatively low thermal conductivity of the PCM, a TCE is incorporated into the PCM to boost its conductivity. The TCU structure is complex, and modeling an electronic device with it requires time and effort. Hence, this research develops approximate, yet effective, solutions for modeling the TCU, which employ effective thermo-physical properties. The TCU component properties are averaged and a single TCU material is considered. This approach is evaluated by comparing the numerical predictions with the experimental results. The numerical model is then used to study the effect of important parameters that are experimentally expensive to examine, such as the PCM latent heat, Stefan number, and heat source power. It is shown that the TCU can provide a reliable solution to portable electronic devices, which avoids overheating and thermally-induced fatigue, as well as a solution which satisfies the ergonomic requirement.
\end{abstract}

Index Terms-Phase change material, portable electronics, thermal conductivity enhancer, thermal management.

\section{NOMENCLATURE}

Symbols

$C_{p} \quad$ Specific heat.

$\bar{C}_{p} \quad$ Apparent heat capacity.

$g \quad$ Acceleration of the gravity.

Gr Grashof number.

$h \quad$ Heat transfer coefficient.

$h_{r} \quad$ Radiation coefficient of heat transfer.

$h_{\text {eff }} \quad$ Effective coefficient of heat transfer.

$k \quad$ Thermal conductivity.

$L \quad$ Latent heat of fusion.

$L_{c} \quad$ Characteristic length.

$N \quad$ Number of electronic components in a device.

$\mathrm{Nu} \quad$ Nusselt number.

PCM Phase change material.

Pr Prandtl number.

\footnotetext{
Manuscript received September 18, 2002; revised January 7, 2003. This work was supported by the HERETIC Program under DARPA Grant 00014-99-0481, the NSF Grant CTS-0103082, and the DCED Pennsylvania Infrastructure Technology Alliance (PITA). This work was recommended for publication by Associate Editor Y. K. Joshi upon evaluation of the reviewers' comments.

E. M. Alawadhi is with the College of Engineering and Petroleum, Department of Mechanical Engineering, Kuwait University, Safat 13060, Kuwait (e-mail: esam@kuc01.kuniv.edu.kw).

C. H. Amon is with the Department of Mechanical Engineering, Institute for Complex Engineered Systems, Carnegie Mellon University, Pittsburgh, PA 15213 USA (e-mail: camon@cmu.edu).

Digital Object Identifier 10.1109/TCAPT.2003.811480
}

\author{
$Q \quad$ Heat generation per unit volume. \\ $R \quad$ Residual. \\ $\mathrm{Ra} \quad$ Rayleigh number. \\ St Stefan number. \\ T Temperature. \\ $t \quad$ Time. \\ TCE Thermal conductivity enhancer. \\ TCU Thermal control unit. \\ TIA Technical information assistant. \\ V Volume. \\ Greek Symbols \\ $\beta \quad$ Thermal expansion. \\ $\varepsilon \quad$ Emissivity. \\ $\rho \quad$ Density. \\ $\sigma \quad$ Boltzmann constant.
}

Subscripts

$s \quad$ Surface.

$\infty \quad$ Ambient.

\section{INTRODUCTION}

$\mathbf{T}$ HE RELIABILITY of an electronic component is defined as the ability of performing a required function under given conditions for a stated time [1]. An electronic device fails to fulfill its intended function when its application or environmental condition exceeds its application limit. A survey from the U.S. Air Force [2] indicates that the percentage of temperature related failures in electronics exceeded $55 \%$. This high percentage is evidence that the current cooling methods are inadequate to fulfill the device cooling requirement. Advances in electronic packaging and increases in chip complexity and functionality lead to this high percentage. Theoretically, electronic components are very reliable at recommended operating temperatures [3]. However, environmental factors and unusual operating situations greatly decrease the effective operating time. Mithal [4] studied the effect of temperature on electronic component reliability. The experimental results indicate that a $1{ }^{\circ} \mathrm{C}$ decrease in a component temperature may lower its failure rate by as much as $4 \%$. Moreover, the research indicates that a $10{ }^{\circ} \mathrm{C}$ to $20{ }^{\circ} \mathrm{C}$ increase in component temperature may increase its failure rate by $100 \%$.

Portable electronic devices such as notebook computers and wearable electronic devices possess unique characteristics that nearly eliminate the use of traditional methods of thermal management. They are highly sophisticated computers employed to assist their users in unusual environments. Since users will wear 


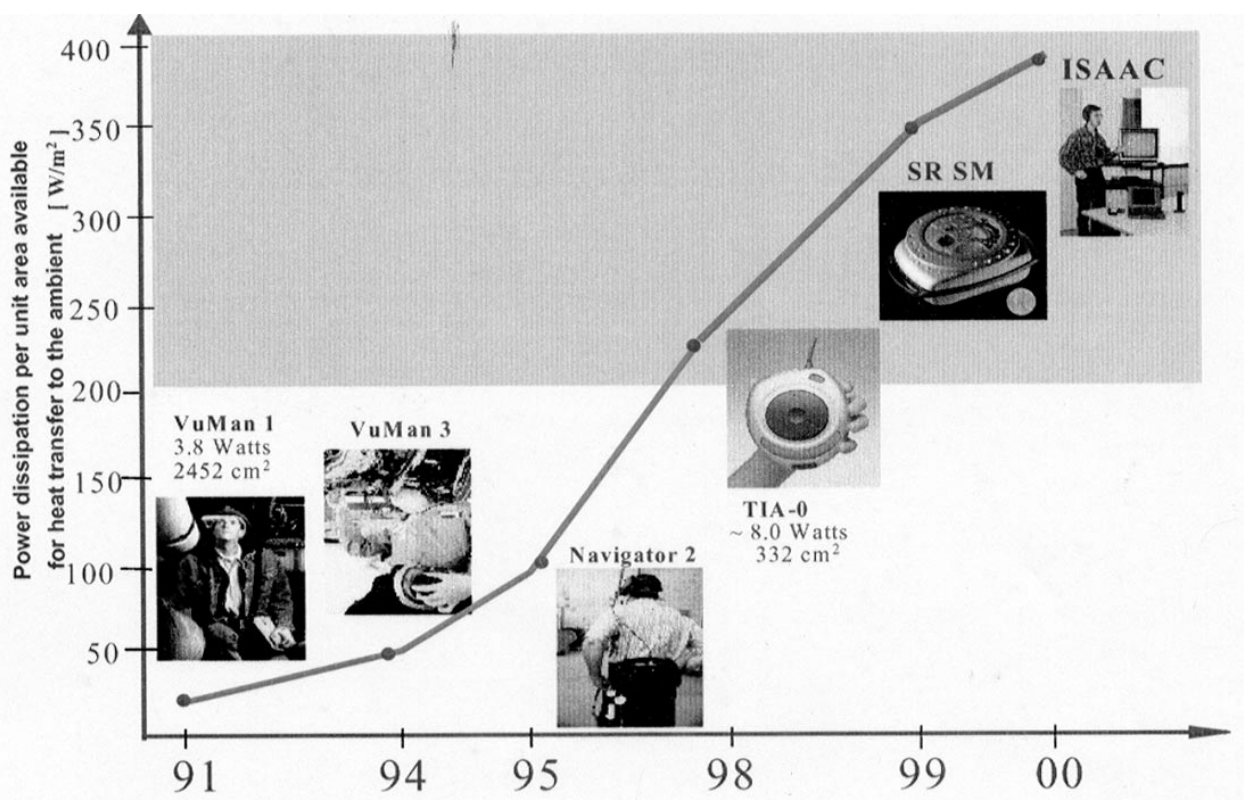

Fig. 1. Power dissipation per unit area available for heat transfer to ambient for CMU wearable electronic devices in the last ten years.

or carry the devices during duty time, these devices are required to be light in weight and compact. In addition, they are required to be completely sealed because they are designed to operate in wet and dusty environments. Ventilation slots allow ambient air to circulate in the device and may damage the device's sensitive components. Therefore, they are not preferable due to the working environment. Extended surfaces can be placed on the device's outer surface, but these are undesirable because their relatively high weight increases the device's size. Cooling fans are also not a preferred method of cooling because of the noise they produce and the additional energy they consume from the device's battery. When natural convection on the external case is the only means of heat dissipation, thermal managements of electronic devices have reached their limit in controlling the excessive heat that is generated in the main processor and other components. If the workload is too heavy, natural convection cannot balance the internally generated heat. Thus, heat will be accumulated in the device and a failure due to overheating is likely to occur. Active thermal management may prevent the device from overheating, but cyclic bursts of power generation increase the possibility of failure due to thermal fatigue. The electronic components' reliability is highly affected by these types of operations.

Fig. 1 shows Carnegie Mellon University's wearable computers, which have been designed and manufactured in the last ten years [5]. This figure shows power dissipation per unit area available for heat transfer to the ambient. This figure indicates that during the last ten years, the power dissipation per unit area has increased dramatically, due to a continuous increase of dissipated power and a continuous decrease of device size. The operating time of these wearable computers is limited to a few hours, thus motivating the need for a new method of thermal management.

\section{A. Thermal Management With Phase Change Materials}

A thermal control unit (TCU) has several attractive features that can fulfill the cooling needs for portable electronic devices with a limited operation duration of a few hours. The TCU is composed of phase change material (PCM) and a thermal conductivity enhancer (TCE). The TCU's primary function is to absorb the excessive heat that is generated in the heat source component during operating time by allowing the PCM to melt, and then releasing it during OFF time while keeping the electronic outer surface temperature relatively low and comfortable to the user's skin. The TCE is used to make the melting and freezing of the PCM uniform. Once the component temperature reaches the PCM melting temperature, the PCM melts and absorbs heat until it is completely melted. During this period, the component temperature is almost constant and a steady state temperature is delayed, allowing additional operating time before reaching the component's maximum temperature. Relatively high amounts of energy can be stored in small quantities of PCM because of the latent heat of the PCM.

The TCU can also be useful to other applications, such as the thermal management of an electronic device with cyclic bursts of power. The TCU can act in conjunction with the varying power, stabilizing the varying electronic temperature for a significant time. During ON time, the PCM absorbs part of the generated heat. During OFF or low power periods, the PCM releases the stored heat into the ambient air. The PCM decreases the temperature fluctuating band during PCM melting, and also reduces the fluctuating average temperature.

Leoni and Amon [6] built a numerical model for the TCU, with the objective of investigating the performance of the TCU under different geometry layouts and the effect of using PCMs with different melting temperatures. The TCU is embedded in epoxy polymer [7] that simulates an electronic device embedded in a wearable computer [8], and a heat source unit is attached to the thermal control unit. To control the temperature for a specific electronic component, completely enclosing the heat source component by the thermal control unit is recommended for best performance. Experimental and numerical investigations were performed by Vesligaj and Amon [9]. The physical 
experiments were conducted to study the performance improvement by introducing a PCM thermal control unit into an electronic device model. The numerical calculations predict that the TCU can improve the system's performance during time dependent operating conditions by dampening the heat source temperature fluctuations during PCM melting. The boundary conditions and thermal conductivity of the polymer composite substrate have a significant effect on the TCU's performance because they affect the heat path in the system.

Gauche and $\mathrm{Xu}$ [10] examined a compact system that contained a main printed circuit board with a central processing unit. A hybrid-cooling device consisting of an extended surface and a PCM package is placed on the main processor. The PCM package absorbs heat from the circulating air and from the processor. Estes [11] studied the effect of a PCM heat storage package inside telecommunication plant electronic enclosures on the system's temperature. A PCM layer covers the enclosure, and varying and constant power operations are both considered. The electronic operating condition is improved after introducing the PCM. A comprehensive study for passive thermal control of a plastic quad package by using PCM was performed by $\mathrm{Pal}$ and Joshi [12]. A PCM package is incorporated under a printed wiring board. While the PCM is melting, there is a natural convection flow in the enclosure. The effect of the thermal conductivity of the printed board is considered in the investigation. They found that the PCM could hold the chip temperature rise for a substantial amount of time.

\section{B. Thermal Control Unit Component}

The thermal control unit is composed of phase change material (PCM) and thermal conductivity enhancer (TCE). The PCM selection criteria and types are described in this section, along with TCE materials and design.

Phase Change Material: Compared to other thermal management techniques for electronic devices, thermal control by using PCM is a new approach. There are over 500 potential PCM candidates that are reviewed in literature [13]. However, few materials have actually been tested and used for PCM electronic applications. The PCMs are selected on the basis of their heat of fusion and melting temperatures. However, many PCMs have a high latent heat of fusion and a convenient melting temperature but are hazardous or highly corrosive. Therefore, the PCM must exhibit certain desirable thermodynamic and chemical properties. In addition, economic considerations and availability at large scales must also be considered.

The various criteria that control the PCM selection for the thermal control units are listed in Abhat's report [14], and the PCM selection depends on the application. In general, the PCM should possess the following criteria: the PCM melting temperature should be lower than the device's maximum operating temperature; the latent heat of fusion must be high, allowing a small amount of PCM to store a large amount of energy; high specific heat is desirable, which will provide additional sensible heat storage capacity; it must have high thermal conductivity, which makes the PCM melting and solidification homogenous and could also prevent potential PCM overheating; it must have chemical stability, so that the PCM will not be changed periodically; the PCM must be nonpoisonous, nonflammable, and non-
TABLE I

PCMS AND THEIR PROPERTIES

\begin{tabular}{l|cccc}
\hline \multicolumn{1}{c|}{ PCM } & $\begin{array}{c}\mathrm{T}_{\mathrm{m}} \\
\left({ }^{\circ} \mathrm{C}\right)\end{array}$ & $\begin{array}{c}\mathrm{L} \\
(\mathrm{kJ} / \mathrm{kg})\end{array}$ & $\begin{array}{c}\text { Density } \\
\left(\mathrm{kg} / \mathrm{m}^{3}\right)\end{array}$ & $\begin{array}{c}\mathrm{k} \\
(\mathrm{w} / \mathrm{m} . \mathrm{K} .)\end{array}$ \\
\hline Octadecane & 28.0 & 244.0 & 774 & 0.35 \\
\hline Eicosane & 36.8 & 241.0 & 778 & 0.27 \\
\hline Cpric & 31.5 & 153 & $884\left(40^{\circ} \mathrm{C}\right)$ & 2.0 \\
\hline Caprilic & 16.3 & 149 & $\begin{array}{c}1033\left(10^{\circ} \mathrm{C}\right) \\
861\left(80^{\circ} \mathrm{C}\right)\end{array}$ & 2.0 \\
\hline $\mathrm{Zn}\left(\mathrm{NO}_{3}\right)_{2} 6 \mathrm{H}_{2} \mathrm{O}$ & 36.4 & 147 & 2065 solid & 0.31 \\
\hline
\end{tabular}

explosive. The most critical properties are PCM melting temperature and latent heat of fusion. The PCM thermal conductivity is not critical because it could be improved by using a thermal conductivity enhancer. PCMs are grouped into the families of either organic or inorganic. Sub-families of the organic materials include paraffin and nonparaffin organics. The thermal conductivity of paraffins is very low and comparable to insulators.

Paraffins should not be exposed to high temperature because all organic materials are flammable. Several paraffins and nonparaffins have melting points within the desired range, and high latent heat would satisfy the storage requirements. However, the requirement that the thermal control unit be nonflammable eliminates these candidates. However, salts hydrates are successful substitutes for organic PCMs. They are nonflammable, have high heat of fusion, and their melting temperatures range from $18.5^{\circ} \mathrm{C}$ to $116.0^{\circ} \mathrm{C}$, making them ideal for thermal design considerations of electronic devices. The major problem with using salt hydrates for PCMs is that they are highly corrosive. Table I shows commonly used PCMs as phase change material, and properties are obtained from the Phase Change Material Handbook by Hale et al. [13]. Eicosane has been used as a PCM in this research because its melting temperature is within the desired operating temperature of the TIA. Its properties do not significantly change with temperature. However, its properties are different in each phase. For the numerical simulations, different constant properties in solid and liquid phases are used as well as during PCM melting.

Thermal Conductivity Enhancer: One major issue that needs to be addressed is that all phase change materials with high latent heat storage capacity have unacceptably low thermal conductivity, which makes heat charging and discharging slow during PCM melting. An increase in the heat transfer during PCMs phase change with low thermal conductivity is demonstrated by inserting a highly conductive metal matrix into the PCM. The matrix is dispersed in the PCM so that the mixture behaves thermally like a homogenous material with both high thermal conductivity and high heat capacity [7]. Practically, an application imposes a size limitation in the TCU, and the TCE reduces the volume available for the PCM. Therefore, when considering the thermal storage capacity, the heat storage capacity of the PCM is displaced by a specific heat temperature rise product for the TCU, which is much lower than PCMs latent heat capacity. Hence, the TCE's size and design should be carefully measured and performed. 

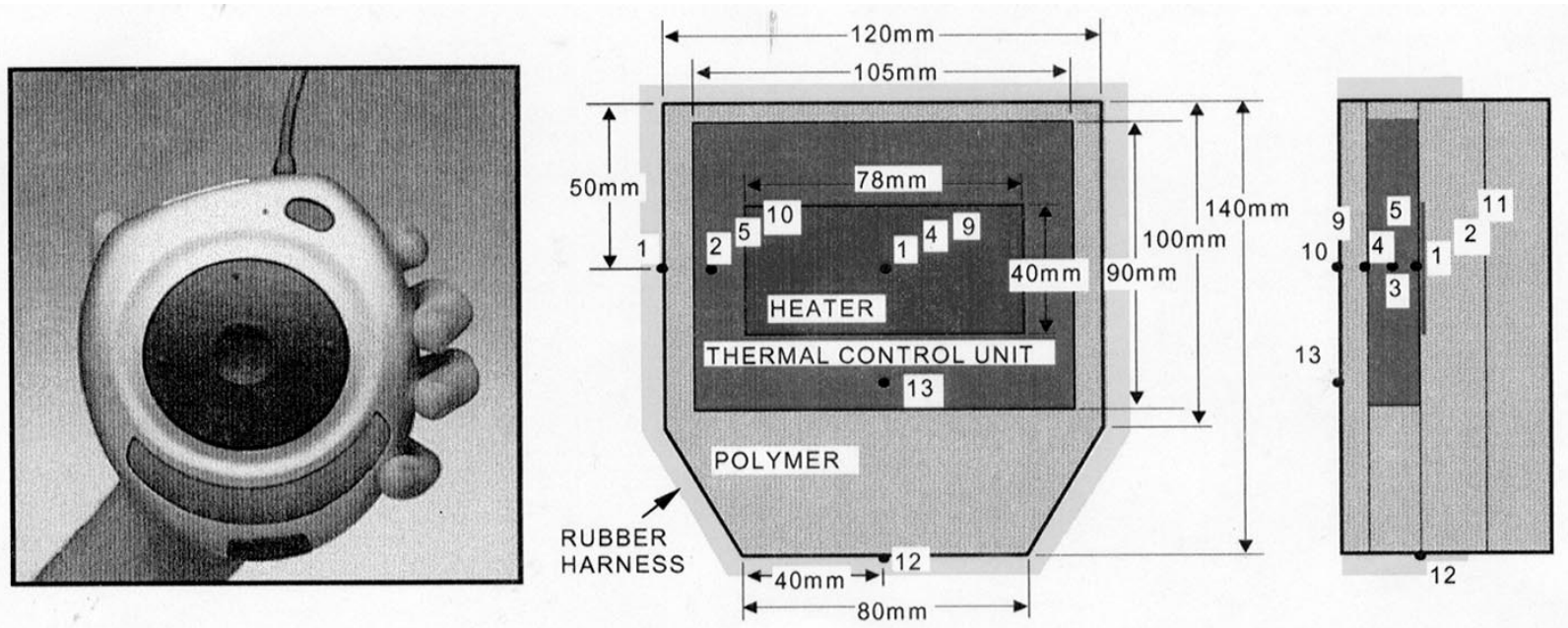

Fig. 2. Technical information assistant (TIA), wearable computer, and location of the thermocouples.

Aluminum, titanium and stainless steel are the metals used for the TCE. The thermal conductivity of these metals is high. They are corrosion resistant and high in strength to weight ratio. Aluminum is widely used because of its low density, high thermal conductivity, and corrosion resistance. It can be soldered, brazed, and welded. In addition, aluminum-aluminum joints are generally superior in strength to joints between aluminum and dissimilar metals. Straight fins are used in computational studies for preliminary analyzes and performance predictions, since modeling a metal honeycomb or foam matrix demands greater effort. The fins in numerical studies can simulate the metal honeycomb or foam matrix in a practical, properly modeled system.

\section{EXPERIMENTAL AND NUMERICAL TCU MODELS}

The experimental model is a prototype of a Technical Information Assistance (TIA), a wearable computer where the thermal control unit is embedded in the electronic device. The objective of the experimental work is to verify the numerical model and to ensure the effectiveness of the TCU under realistic operating conditions. The numerical model is then employed to study the effect of important factors that are experimentally expensive to obtain, such as the effect of the Stefan number.

\section{A. Experimental Model}

The TIA physical model is designed and manufactured for physical experiments [15] at the shape deposition-manufacturing laboratory at Carnegie Mellon University [16]. The experimental model, shown in Fig. 2, contains a thermal control unit (TCU), which is an aluminum enclosure, with aluminum foam impregnated with Eicosane PCM. The TCU's dimensions are $101 \times 68 \times 12 \mathrm{~mm}^{3}$ and its weight is $132 \mathrm{~g}$. The PCM's quantity in the TCU is $62.5 \mathrm{~g}$ and $20 \%$ of the TCU's total volume is left empty to account for the PCM thermal expansion upon melting. The aluminum foam was obtained from Energy Research and Generation, Inc. and is $8-9 \%$ aluminum by volume. The aluminum foam is wrapped by an aluminum sheet to seal the TCU, and the thickness of the aluminum sheet is
$0.76 \mathrm{~mm}$. A strip heater with nominal resistance of $9.1 \Omega$ is attached to the backside of the TCU. The heater uses high thermal conductivity silicon grease that is applied to minimize the resistance of the joints.

The TCU is embedded in an epoxy polymer, Stycast $2651 \mathrm{~mm}$ black, obtained from Grace Specialty Polymers. The thermal conductivity of the epoxy is $0.6 \mathrm{w} / \mathrm{m} . \mathrm{K}$., and the epoxy quantity in the TIA is $350 \mathrm{~g}$. The building procedure of the TIA's model follows the layout manufacturing process of shape deposition manufacturing [17]. Heat is dissipated to the environment from the front face of the TIA and the rubber harness while the backside of the TIA is insulated. The total area available for free convection and radiation is approximately $350 \mathrm{~cm}^{2}$.

An experimental set up and automated data acquisition system is used to obtain temperature data from the TIA epoxy model. Thirteen thermocouples are positioned in and on the TIA model. The temperature histories of the heat source and the TIA outer surface are of interest. All thermocouples are K type and obtained from OMEGA Inc. OMEGA's specification on this type of thermocouple gives a working temperature range of 0 to $1250{ }^{\circ} \mathrm{C}$ with an error of $\pm 0.75^{\circ} \mathrm{C}$. The thermocouples are attached to the TIA's surface area by using OMEGA bond 100 , an adhesive belonging to OMEGA's group of high thermal conductivity epoxies. The thermocouple wires are connected to the analog input channel on the data acquisition connector board. The connection board is obtained from Data Translation, and the model is DT707-T. The temperature signals from the connection board are transferred to the PC, using an eight channel data acquisition board; model DT 2081. The strip heater wires are connected to the dc power supply which is capable of supplying $0-12$ voltage or $0-12$ amperes. A digital voltmeter is used to measure the actual strip heater resistance. Along with the power supply, the strip heater's dissipated power can be determined.

\section{B. Numerical Model}

The objective of performing this numerical study is to answer several TCU design questions. In the numerical simulations, the effect of the coefficient of heat transfer can easily be examined 


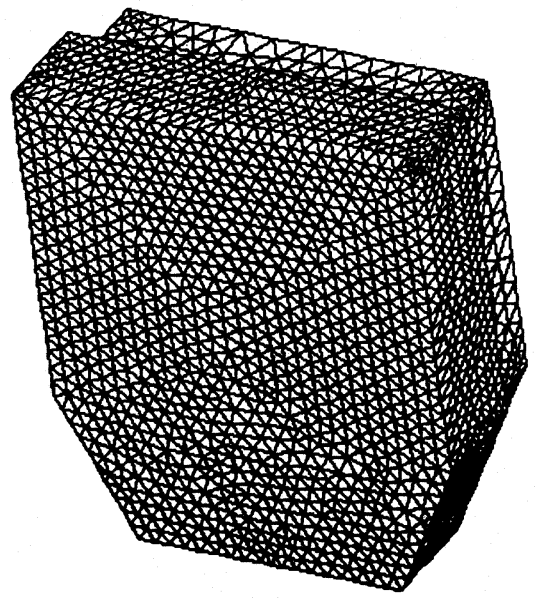

Fig. 3. Finite elements model of the TIA wearable computer.

whereas it is expensive to perform this procedure in the physical model. In addition, the effect of the latent heat of fusion on the PCM can be examined in the numerical analyses by changing the PCM properties in the code rather than physically replacing another PCM. Moreover, the numerical solution for the TIA enables us to examine the temperature distribution, locate the hot spots, and examine temperature distributions for high power applications.

The numerical model replicates the physical model, and the temperature history of the heat source and outer surface area is obtained by assigning history points at these locations. These locations are the same as the corresponding thermocouple locations in the physical model. To ensure the accuracy of the numerical model and the proposed assumptions, a comparison between the experimental and numerical models is performed first. The dimensions and geometry of the TIA were previously presented in the experimental section. Finite elements method is utilized to study the effectiveness of the TCU for the electronic device. The mesh of the 3-D model is shown in Fig. 3, and the computational domain consists of 15000 elements. To ensure that the results are mesh independent, the results of a model with 20000 elements is compared with one having 15000 elements in terms of temperature distribution at the steady state condition and the behavior of the two history points. The discrepancies obtained were less than $0.5 \%$, and the model with 15000 elements is selected for performing the numerical investigations because it takes less CPU time. In addition, it was verified that the time step of $5 \mathrm{~s}$ provides good temporal resolution. The computational mesh is dense at the heat source and the thermal control unit, while it is coarse at the insulated side of the TIA. Notice that the heat source fine mesh cannot be viewed from Fig. 3 because it is embedded in the TIA. Heat is generated only at the heat source, and the TCU volume is attached to the heat source.

\section{Calculating Effective Thermo Physical Properties of the TCU}

The structure of the TCU is complex, containing PCM, thermal conductivity enhancer, and air. Detailed modeling of an electronic device with this complex TCU is computationally challenging. Therefore, approximating the TCU
TABLE II

THERMO-PHYSICAL PROPERTIES OF TCU COMPONENTS

\begin{tabular}{c|cccc}
\hline Component & $\begin{array}{c}\mathrm{k} \\
(\mathrm{w} / \mathrm{m} . \mathrm{K})\end{array}$ & $\begin{array}{c}\mathrm{C}_{\mathrm{p}} \\
(\mathrm{kJ} / \mathrm{kg} \mathrm{K})\end{array}$ & $\begin{array}{c}\rho \\
\left(\mathrm{kg} / \mathrm{m}^{3}\right)\end{array}$ & $\begin{array}{c}\mathrm{L} \\
(\mathrm{kJ} / \mathrm{kg})\end{array}$ \\
\hline PCM & $\begin{array}{c}0.39(\mathrm{~S}) \\
0.157(\mathrm{~L})\end{array}$ & $\begin{array}{c}1.90(\mathrm{~S}) \\
2.20(\mathrm{~L})\end{array}$ & $\begin{array}{c}810(\mathrm{~S}) \\
770(\mathrm{~L})\end{array}$ & 241 \\
\hline TCE & 179.96 & 0.96 & 2712.6 & 0 \\
\hline Air & 0.0263 & 1.007 & 1.164 & 0 \\
\hline $\begin{array}{c}\text { TCU } \\
\text { housing }\end{array}$ & 179.96 & 0.96 & 2712.6 & 0 \\
\hline
\end{tabular}

thermo-physical properties is essential for modeling and performing parametric studies of the TIA. In this research, average properties based on the TCU component's volume are used in the numerical model. This approximate method is proposed by Chow [18], who examined the validity of modeling the TCU with average material properties by comparing its results with a TCU with multimaterial composition. A strong agreement was found between the two cases. The effective thermo-physical properties of TCU components are shown in Table II. The TCU's effective thermal conductivity, specific heat, specific heat during PCM melting and density are defined as

$$
\begin{aligned}
k_{e f f} & =\frac{\sum\left(k_{i}\right) V_{i}}{\sum V_{i}} \\
C_{P_{\text {eff }}} & =\frac{\sum\left(C p_{i}\right) V_{i}}{\sum V_{i}} \\
C_{P_{\text {eff }}} & =\frac{\sum\left(C p_{i}+(L / \Delta T)\right) V_{i}}{\sum V_{i}} \quad \text { (PCM melting) } \\
\rho_{\text {eff }} & =\frac{\sum\left(\rho_{i}\right) V_{i}}{\sum V_{i}} .
\end{aligned}
$$

The latent heat of the epoxy polymer and aluminum composite is set to zero because the storage media is always kept at a temperature below the melting point. Table III shows TCU average properties that are used in the numerical simulations.

\section{Boundary Conditions}

The imposed boundary conditions are the same as in the experimental model. The coefficient of heat transfer is obtained from the working correlation for free convection. Since the front side is a vertical plane, while the top and bottom sides have horizontal planes, different correlations have been used. The correlation formulae are for natural convection only, and the radiation effect should be counted by using the radiation coefficient of heat transfer, defined as

$$
h_{r}=\frac{\varepsilon \sigma\left(T_{s}^{4}-T_{s \infty}^{4}\right)}{\left(T_{s}-T_{\infty}\right)}
$$

where $\varepsilon$ is the surface emissivity and $\sigma$ is the Boltzmann constant. The effective coefficient of heat transfer is the sum of the convection and radiation coefficients. Each surface subject to convective and radiation heat transfer is treated independently, and the effective coefficient of heat transfer is obtained at each surface. 
TABLE III

TCU AVERAGe Properties

\begin{tabular}{l|ccc}
\hline & $\mathrm{k}$ & & \\
& $(\mathrm{w} / \mathrm{m} . \mathrm{K})$ & $\begin{array}{c}\mathrm{C}_{\mathrm{p}} \\
(\mathrm{J} / \mathrm{kg} \mathrm{K})\end{array}$ & $\begin{array}{c}\text { Density } \\
\left(\mathrm{kg} / \mathrm{m}^{3}\right)\end{array}$ \\
\hline PCM solid & 39.66 & 1514.57 & 1065.51 \\
\hline PCM melting & 39.60 & 101520.00 & 1053.88 \\
\hline PCM liquid & 39.53 & 1688.96 & 1042.25 \\
\hline
\end{tabular}

Free Convection Past Vertical Plane Surface: Incropera and DeWitt [19] have documented experimental investigations for free convection past vertical plane surface, and recommend the following relation for laminar free convection:

$$
\begin{gathered}
N u_{L}=0.68+0.67 R a_{L}^{1 / 4}\left[1+\left(\frac{0.492}{\operatorname{Pr}}\right)^{9 / 16}\right]^{-4 / 9} \\
\text { for } 0<R a<10^{9} .
\end{gathered}
$$

The Nusselt and Rayleigh numbers are based on the total length, which corresponds to the height of the TIA. The Rayleigh number is defined as

$$
R a=G r \operatorname{Pr}=\frac{L^{3} g \beta \Delta T \operatorname{Pr}}{\nu^{2}}
$$

where $\beta$ is the air thermal expansion, and is equal to the reciprocal of the air temperature when air is assumed an ideal gas.

Free Convection Past Horizontal Plate: There are two cases for free convection past a horizontal plate, top heated and bottom heated. The top surface of the TIA is top heated while the bottom side is bottom heated. The following correlation for laminar free convection is widely used. Heated plate facing up

$$
N u_{L C}=0.54 R a_{L c}^{1 / 4} \quad \text { for } 2.6 \times 10^{4}<R a_{L c}<10^{7} .
$$

Heated plate facing down

$$
N u_{L C}=0.27 R a_{L c}^{1 / 4} \quad 3 \times 10^{5}<R a_{L c}<3 \times 10^{10}
$$

where

$$
L_{c}=(\text { Plate Area }) /(\text { convection past inclined plate }) .
$$

Free Convection Past Inclined Plate: For a heated inclined surface, Incropera and Dewitt [19] recommend that for $0 \leq \theta \leq$ $60, g$ be replaced by $(g \operatorname{Cos} \theta)$ in the correlation for the vertical plate.

Insulated Boundary Condition: Setting zero heat flux on the insulated boundary condition simulates adiabatic Newman boundary condition

$$
\frac{\partial T}{\partial n}=0
$$

Since the boundary's temperature is not uniform, the average temperature on each surface is assumed to be the average of the
TABLE IV

AvERAGe COEFFICIENT OF HEAT TRANSFER OF THE TIA'S SURFACES

\begin{tabular}{c|ccc}
\hline Plane & $\begin{array}{c}\mathrm{h}_{\text {conv }} \\
(\mathrm{w} / \mathrm{m} . \mathrm{K})\end{array}$ & $\begin{array}{c}\mathrm{h}_{\mathrm{rad}} \\
(\mathrm{w} / \mathrm{m} . \mathrm{K})\end{array}$ & $\begin{array}{c}\mathrm{h}_{\mathrm{eff}} \\
(\mathrm{w} / \mathrm{m} . \mathrm{K})\end{array}$ \\
\hline Vertical & 7.68 & 5.05 & 12.73 \\
\hline Inclined & 6.39 & 5.05 & 11.44 \\
\hline $\begin{array}{c}\text { Horizontal } \\
\text { (Top heated) }\end{array}$ & 9.37 & 5.05 & 14.42 \\
\hline $\begin{array}{c}\text { Horizontal } \\
\text { (Bottom heated) }\end{array}$ & 4.62 & 5.05 & 9.67 \\
\hline
\end{tabular}

initial condition and the steady state temperature. The properties are calculated at $T_{m}$, except for $\beta$, which is calculated at $T_{\infty} . \Delta T$ in the Grashoff number is the temperature difference between the ambient air and the surface temperature. The $T_{m}$ and $\Delta T$ are defined as

$$
\begin{aligned}
T_{m} & =\frac{T_{s}+T_{\infty}}{2} \\
\Delta T & =T_{s}-T_{\infty}
\end{aligned}
$$

where $T_{s}$ is the surface temperature of the electronic device. Table IV shows convective, radiation and average coefficients of heat transfer for each surface.

The heat transfer coefficient at the vertical surface is $12.73 \mathrm{w} / \mathrm{m} . \mathrm{K}$. On the other hand, the heat transfer coefficient at this surface obtained experimentally by Leoni and Amon [20] is $11.8 \mathrm{w} / \mathrm{m} . \mathrm{K}$. The difference is due to the uniform surface temperature and time-independent temperature assumptions for all surfaces. However, this difference is small, which validates the proposed assumptions in calculating the coefficient of heat transfer. An average coefficient of heat transfer for all surfaces is used in the numerical analysis, defined as

$$
h=\frac{\sum\left(A h_{e f f}\right)_{i}}{\sum A_{i}}
$$

where $A$ is the surface area. The calculated heat transfer coefficient is $13.5 \mathrm{w} / \mathrm{m} . \mathrm{K}$, which is used for all examined powers.

\section{E. Modeling PCM Phase Change}

The method that is widely used to simulate a phase change is the apparent heat capacity method. This method effectively makes any heat transfer software capable of simulating a phase change if the specific heat can be a function of temperature. Thermodynamically, the sum of sensible and latent heats is the 
enthalpy, and the specific heat is the rate of change of the enthalpy with respect to temperature

$$
C_{P}=\frac{\partial h}{\partial T} .
$$

The sum of sensible and latent heats is defined as the apparent heat capacity in the energy conservation equation

$$
\bar{C}_{P}=C_{P}+\frac{\partial L}{\partial T} .
$$

The term $\partial L / \partial T$ is equal to zero at the solid and liquid phases. This term can be approximated as

$$
\frac{\partial L}{\partial T} \cong \frac{\Delta L}{\Delta T} .
$$

This approximation is valid when the transition temperature range $\Delta T$ is of the order of $1{ }^{\circ} \mathrm{C}$ [21]. The released latent heat $\Delta L$ is a function of temperature, but it can be approximated as constant. The following is a definition of the apparent heat capacity method:

$$
\bar{C}_{P}= \begin{cases}C_{P} & T \leq T_{m} \\ C_{P}+\frac{L}{\Delta T} & T_{m}<T<T_{m}+\Delta T \\ C_{P} & T \geq T_{m}+\Delta T\end{cases}
$$

where $T_{m}$ is the PCM melting temperature and $\Delta T$ is the transition temperature range. The buoyancy effect of the liquid PCM is negligible because the TCE metal structure prevents liquid PCM from moving and makes the TCU's temperature spatially uniform. In this research, the buoyancy effects and thermal expansion were neglected for modeling simplification.

\section{RESUlT AND Discussions}

Both constant and varying heat source powers are examined in the experimental and numerical investigations. The aim of experimental work is

a) to ensure that the proposed TCU model has an acceptable level of accuracy for engineering applications under practical situations;

b) to examine the effectiveness of the thermal conductivity enhancer;

c) to measure melting time of the PCM.

On the other hand, the numerical model is employed to examine TCU thermal design factors that are expensive to be examined experimentally, such as the effect of the Stefan number.

\section{A. Constant Power Operation}

The objective of the implementation of PCM in portable electronic devices is to extend their operating time. Hence, the potential device overheating could be prevented and its surface temperature could be lower than what could harm the user's skin [15]. Heat is generated at the heat source. The device initial temperature and the ambient temperature is $20^{\circ} \mathrm{C}$. Fig. 4 shows experimental and numerical temperature histories at the heat source (thermocouple \# 1) for four different constant values of power: $5,6.75,8$, and $10 \mathrm{~W}$.

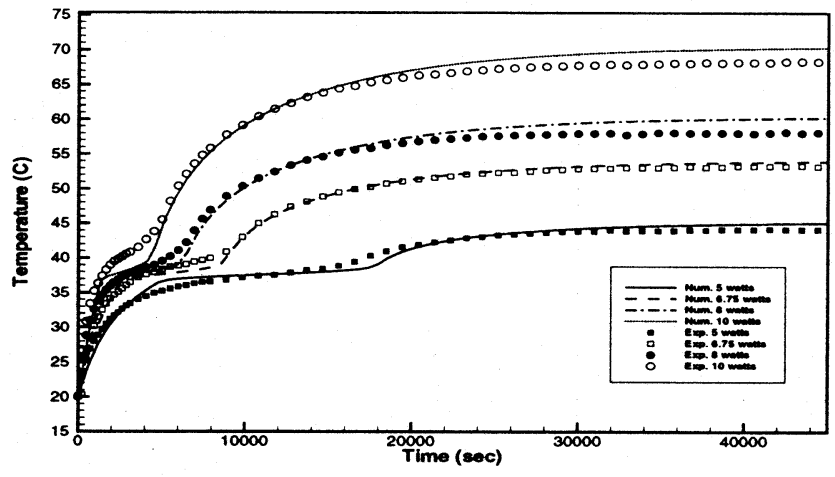

Fig. 4. Experimental and numerical temperature histories of the heat source for four constant powers.

When the heat source power is applied, its temperature starts rising from its initial condition at $20^{\circ} \mathrm{C}$ until it reaches $37^{\circ} \mathrm{C}$. During this period, energy is either stored in the system in the form of sensible heat or transferred to the ambient. Once the heat source reaches $37^{\circ} \mathrm{C}$, which is the PCM melting temperature, the heat source temperature increasing rate decreases, caused by the PCM's heat absorption in the form of latent heat of fusion. During this period, heat is stored in the system in the form of latent and sensible heats. The PCM melting duration is $12600 \mathrm{~s}$ for $5 \mathrm{~W}$. When the PCM is completely melted, heat source temperature starts rising again until it reaches the steady state temperature. The duration for this period is about $21600 \mathrm{~s}$. The steady state temperature of the heat source is about $45^{\circ} \mathrm{C}$. Since the heat source maximum temperature did not exceed the limit for safe and reliable operating conditions, a power of $5 \mathrm{~W}$ is considered to be safe for the device, and there is no limit for the device active power duration.

When $6.75 \mathrm{~W}$ are generated at the heat source, the heat source temperature reaches $50{ }^{\circ} \mathrm{C}$ after $18000 \mathrm{~s}$. The PCM melting duration for this power is $7560 \mathrm{~s}$. The PCM melting time for $6.75 \mathrm{~W}$ is shorter than for $5 \mathrm{~W}$, which is $12600 \mathrm{~s}$, due to the PCM's limited storage capacity. Under steady state conditions, the temperature of the heat source reaches $54{ }^{\circ} \mathrm{C}$, which is $4{ }^{\circ} \mathrm{C}$ above its maximum allowable temperature. The other two powers investigated, 8 and $10 \mathrm{~W}$, are high, but are common operating powers found in modern portable devices. The heat source temperature reaches $50{ }^{\circ} \mathrm{C}$ only after 14000 $\mathrm{s}$ for $8 \mathrm{~W}$, and $7500 \mathrm{~s}$ for $10 \mathrm{~W}$. The experimentally-obtained steady state temperature is $58^{\circ} \mathrm{C}$ for $8 \mathrm{~W}$ and $67^{\circ} \mathrm{C}$ for $10 \mathrm{~W}$, respectively.

Fig. 4 illustrates the good agreement obtained between the experimental and numerical results. The numerical results can accurately predict the PCM melting time, which is an important design parameter for the TCU. In addition, at the steady state condition, the numerical result is also capable of predicting the outer surface temperature with less than a $3 \%$ margin of error. When the PCM is completely melted, the heat source temperature starts to increase until it reaches the steady state temperature. During PCM melting, the experimental results have a slightly higher temperature than the numerical predictions. This difference is caused by PCM overheating, especially at a high heat source power. In the numerical model, the averaging of the thermo-physical properties yields a different heat distribution 


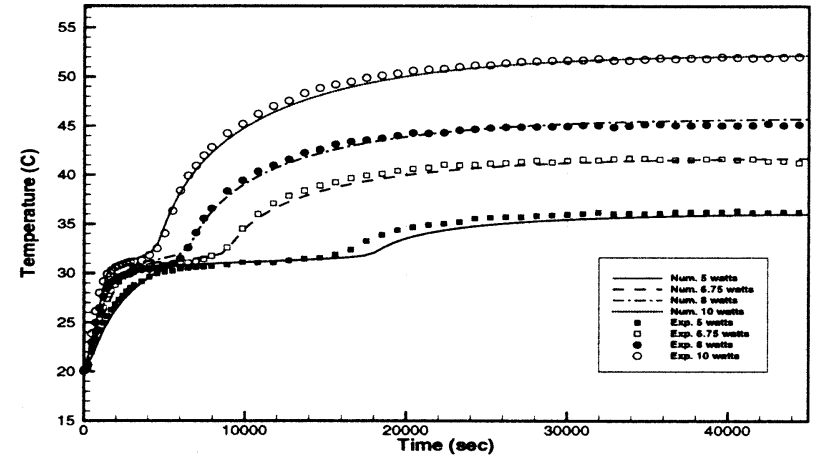

Fig. 5. Experimental and numerical temperature histories of the outer surface for four constant powers.

than the TCU with multi-material composition, especially at an 8 and $10 \mathrm{~W}$ heat source power. In addition, the numerical simulation accurately predicts the melting time for the PCM.

Experimental and numerical temperature histories at the outer surface of the TIA are shown in Fig. 5. Notice that the outer surface does not reach $55^{\circ} \mathrm{C}$, which makes all operating powers safe for the user's skin. A good agreement between the experimental and numerical result is also observed at this location. The comparison between the numerical and experimental results corroborates the proper issue of the use of the effective thermo-physical properties for the TCU and the method of obtaining the coefficient of heat transfer. The following conclusions are drawn from the previous figure.

1) Because the outer surface is relatively far from the TCU and the heat source is attached to the TCU, the predicted heat source temperature is slightly less accurate than the outer surface temperature history. The use of the effective properties affects the heat source temperature predictions with TCE less than the outer surface temperatures.

2) PCM melting time obtained from both experimental and numerical results are very close. This indicates that the apparent heat capacity method for phase change simulation is accurate to predict the actual melting time. In addition, neglecting the free convection in the PCM with TCE and neglecting PCM thermal expansion are valid assumptions, and the effective properties approach is an accurate representation.

3) During PCM melting, the heat source experimental temperature is higher than the numerical result, which indicates that the PCM is overheating and the use of the TCU effective properties approach reduces the effect of PCM overheating. The TCU with this effective property is a more efficient way to distribute heat than the foam matrix.

4) The close agreement between the experimental and numerical results indicates that the methodology of calculating the effective coefficient of heat transfer is accurate for engineering calculations. The outer surface temperature histories of the numerical and experimental results are close to each other. The error is less than $3 \%$ in spite of using the average coefficient of heat transfer rather than local values of the effective coefficient of heat transfer.

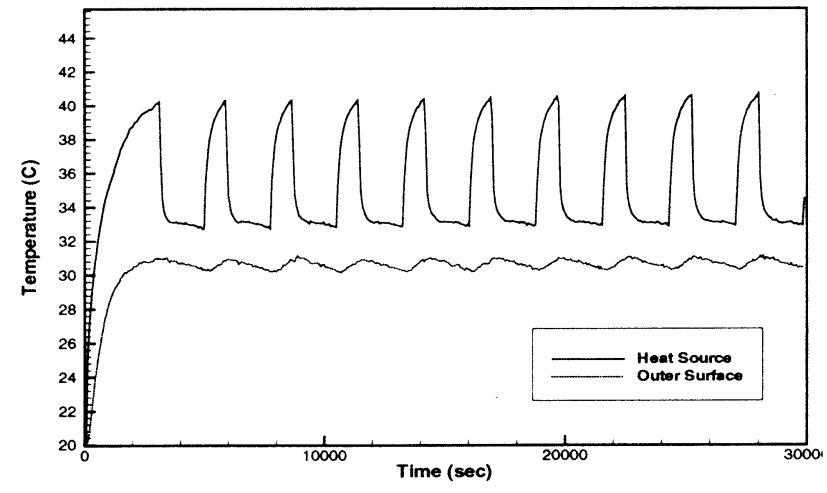

Fig. 6. Experimental temperature history for Case 1 at the heat source and outer surface.

5) When there is no TCU in the device, previous research published by Leoni and Amon [20] indicates that the temperature of the heat source increases without the observed temperature stabilization, as shown in this research.

\section{B. Varying Power Operation}

The prior section has demonstrated that an electronic system with a TCU reduces heat source temperature and extends operating time for constant power operation. However, an electronic device is frequently operated under varying time-dependent power. In this section, two different types of varying powers are examined. The first one is ON/OFF cycles (case 1), where the $\mathrm{ON}$ power is $10 \mathrm{~W}$. This type of duty cycle simulates an electronic device undergoing full power and standby modes. The ON time lasts $900 \mathrm{~s}$ and the OFF time lasts $1800 \mathrm{~s}$. Therefore, the period of each cycle is $2700 \mathrm{~s}$ except that the first cycle lasts for $1800 \mathrm{~s}$ without the OFF power. The initial ON power was used to ensure that the melting process had begun before examining the thermal response of the TCU. The second examined power cycle is varying power with a smaller temperature fluctuation band (case 2) as opposed to case 1. In this duty cycle, a power of $10 \mathrm{~W}$ is generated in the heat source for $900 \mathrm{~s}$, followed by $5 \mathrm{~W}$ for $1800 \mathrm{~s}$, The period of the cycle is $1800 \mathrm{~s}$. This type of duty cycle simulates high and low demands of power, which is a realistic type of operation.

Fig. 6 shows temperature histories for case 1 at two locations: the heat source and the outer surface. The figure indicates that the heat source temperature fluctuates between the PCM melting point and its maximum temperature, which is around $40{ }^{\circ} \mathrm{C}$. In the beginning of the OFF period, the PCM is in liquid phase.

While the PCM temperature decreases to its solidification temperature, the PCM releases the stored energy, taking a long time to completely discharge the latent heat. The energy is discharged to the ambient and its surrounding components such as the heat source. For this generated power, the fluctuating temperature band is $7^{\circ} \mathrm{C}$. On the other hand, the surface temperature of the TIA fluctuates with a smaller temperature fluctuation band, which is $1{ }^{\circ} \mathrm{C}$, and its maximum temperature is $31^{\circ} \mathrm{C}$.

The heat source and the TIA outer surface temperature histories for case 2 are shown in Fig. 7. The OFF period in case 1 is substituted by $5 \mathrm{~W}$. This figure indicates that the heat source 


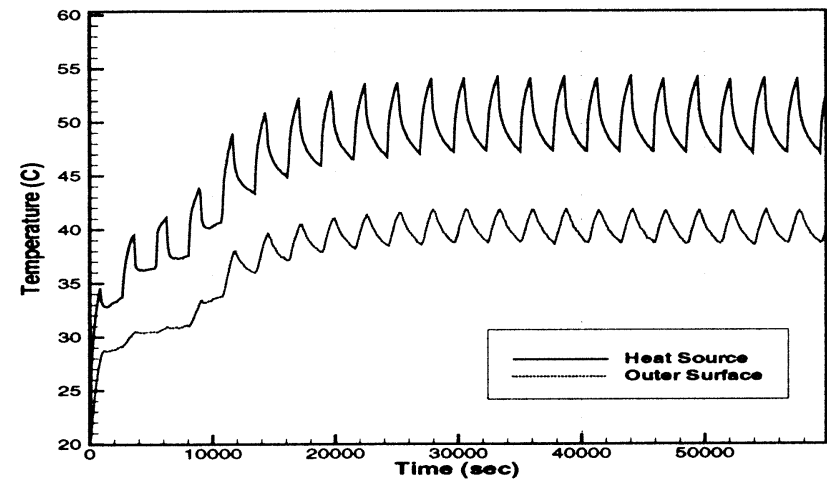

Fig. 7. Experimental temperature history for Case 2 at the heat source and outer surface.

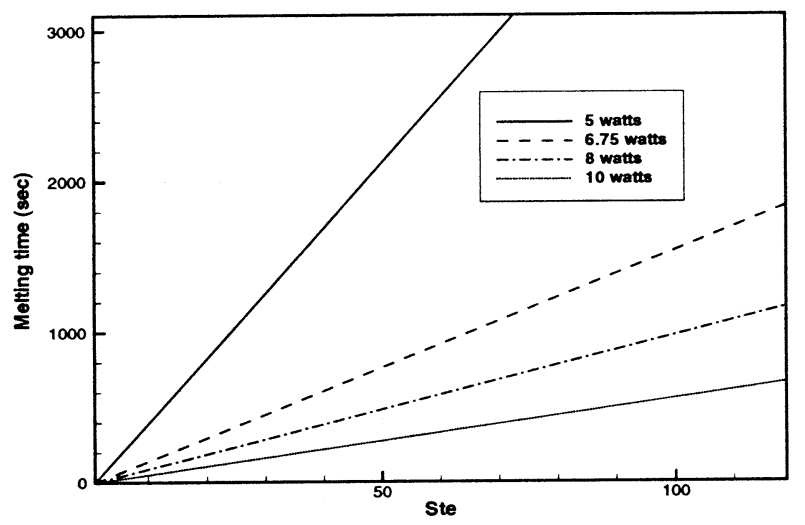

Fig. 8. PCM melting time versus Stefan number for different power dissipations.

reaches a maximum temperature of $54{ }^{\circ} \mathrm{C}$, and it is $9.5^{\circ} \mathrm{C}$ higher than the previously examined case. During PCM melting, which last for $16200 \mathrm{~s}$, the temperature fluctuation band is $5^{\circ} \mathrm{C}$, whereas the steady state temperature fluctuation band is $7.5^{\circ} \mathrm{C}$. In addition, the maximum heat source temperature during PCM melting is $37{ }^{\circ} \mathrm{C}$ which is $12.5^{\circ} \mathrm{C}$ lower than the steady state temperature.

\section{Effect of the Stefan Number}

The effect of the Stefan number on the PCM melting time is shown in Fig. 8, for four heat source powers: $5 \mathrm{~W}, 6.75 \mathrm{~W}, 8 \mathrm{~W}$, and $10 \mathrm{~W}$. The Stefan number is defined as

$$
\text { Ste }=\frac{C_{p} \Delta T}{L}
$$

where $L$ is latent heat of fusion, and $\Delta T$ is the transition temperature. The Stefan number increases the storage capacity of the TCU and does not affect the heat paths in the system. Therefore, there is a linear relationship between the Stefan number and the PCM melting time. This parametric study is useful for determining the required size of the TCU for a given operating power and time extension. By knowing these factors, the Stefan number, which is an indication of the PCM quantity storage size, can be determined.

\section{CONCLUSION}

Experimental and numerical studies were performed to investigate the effectiveness and performance of a thermal control unit (TCU). The aim of the experimental investigation was to ensure the effectiveness of the TCU model under practical conditions, whereas the aim of the numerical investigation was to study the effect of the TCU's components and to optimize their performance. In addition, the technique proposed to model the TCU's complex structure was verified by comparing numerical to experimental results. Afterwards, the numerical model was employed to examine important thermal design parameters, such as the Stefan number and heat source power.

The experimental results demonstrate the TCU effectiveness in controlling the heat source temperature. For constant power operations, the TCU keeps the system's temperature almost constant during PCM melting, which is $37{ }^{\circ} \mathrm{C}$ for Eicosene PCM. For varying power operations, the TCU highly reduces the heat source temperature fluctuations and its average temperature during PCM melting. The PCM melting time period decreases as the heat source power increases in a nonlinear trend for both constant and varying power operations. Furthermore, the PCM melting time increases as a function of the Stefan number.

The numerical prediction for the examined experimental model shows a good agreement between the numerical and experimental results. Therefore, the proposed assumptions in the numerical model are valid for investigating thermal design trends. PCM melting times obtained from both experimental and numerical results indicate that the apparent heat capacity method for phase change simulation is accurate. In addition, neglecting free convection and thermal expansion in the PCM is a suitable engineering approach.

The close agreement between the experimental and numerical results demonstrates that the methodology of calculating the effective heat transfer coefficient and of modeling the TCU with average material properties is a valid approach. The three dimensional numerical analysis illustrates that the heat transfer coefficient does not significantly affect the PCM melting time at a given heat source power for the examined conditions. In addition, the graphical representation of the effect of the Stefan number on the PCM melting time is a useful tool for determining the required size of the TCU for a given operating power and required time.

\section{REFERENCES}

[1] T. Bajenescu and M. Bazu, Reliability of Electronic Component. Berlin, Germany: Springer-Velag, 1999.

[2] L. Yeh, "Review of heat transfer technologies in electronic equipment," J. Electron. Packag., vol. 117, pp. 333-339, 1996.

[3] R. Tummala, E. Rymaszewski, and A. Klopfenstein, Microelectronic Packaging Handbook. New York: Van Nostrad Reinhold, 1989, p. 389.

[4] P. Mithal, "Design of experimental based evaluation of thermal performance of a flichip electronic assembly," in ASME EEP Proceedings. New York: ASME, 1996, vol. 18, pp. 109-115.

[5] C. H. Amon, E. Egan, D. Siewiorek, and A. Smailagic, "Thermal management and concurrent system design of a wearable multicomputer," IEEE Trans. Comp., Packag., Manufact. Technol. A, vol. 20, pp. 128-137, June 1997.

[6] N. Leoni and C. H. Amon, "Thermal design for transient operation of the TIA wearable computer," in Proc. ASME InterPACK '97, vol. 2, 1997, pp. 2151-216. 
[7] E. Egan and C. H. Amon, "Measuring thermal conductivity enhancement of polymer composites: Application to embedded electronics thermal design," J. Enhanced Heat Transfer, vol. 8, pp. 119-135, 2001.

[8] — "Thermal management strategies for embedded electronic components of wearable computers," ASME J. Electron. Packag., vol. 122, no. 2, pp. 98-106, 2000.

[9] M. Vesligaj and C. H. Amon, "Transient thermal management of portable electronic using phase change materials and time varying power dissipation," IEEE Trans. Comp. Packag. Technol., vol. 22, pp. 541-550, Dec. 1999.

[10] P. Gauche and W. Xu, "Modeling phase change materials in electronic using CFD: A case study," in Proc. Int. Conf. High Density Interconnect Syst. Packag., 2000, pp. 402-407.

[11] R. Estes, "The effect of thermal capacitance and phase change on outside plant electronic enclosure," IEEE Trans. Comp., Hybrids, Мапиfact. Technol., vol. 5, pp. 843-849, 1992.

[12] D. Pal and Y. Joshi, "Application of phase change materials to therma control of electronic modules: A computational study," Adv. Electron. Packag., vol. 10, pp. 1307-1315, 1996.

[13] D. Hale, M. Hoover, and M. O'Nill, "Phase change materials hand book," Tech. Rep., NASA Contractor Report, NASA CR-61 363, 1971.

[14] A. Abhat, "Low temperature latent heat thermal storage," in ISPRA Course on Energy Systems and Technology. Holland, The Netherlands: Reidel, 1981, pp. 33-91.

[15] N. Leoni and C. H. Amon, "Transient thermal design of wearable computers with embedded electronic using phase change materials," ASME-HTD, vol. 343, no. 5, pp. 49-56, 1997.

[16] T. Prodan, "Experimental investigation on cooling of portable electronic using phase change materials," M.S. thesis, Carnegie Mellon Univ., Pittsburgh, PA, 1998

[17] C. H. Amon, R. Merz, F. B. Prinz, and K. S. Schmaltz, "Thermal modeling and experimental testing of MD-spray shape deposition processes," in Proc. 10th Int. Heat Transfer Conf., vol. 7, Brighton, UK, 1994, pp. 321-327.

[18] L. Chow, J. Zhaog, and J. Beam, "Thermal conductivity enhancement for phase change materials," Int. Comm. Heat Mass Transfer, vol. 23, no. 1, pp. 91-100, 1996.

[19] F. Incropera and D. DeWitt, Fundamental of Heat Transfer and Mass Transfer, 3rd ed. New York: Wiley, 1990.

[20] N. Leoni and C. H. Amon, "Bayesian surrogates for integrating numerical, analytical and experimental data: Application to inverse heat transfer in wearable computers," IEEE Trans. Comp., Packag. Manufact. Technol. A, vol. 23, pp. 23-33, Mar. 2000.

[21] B. Crowley and J. Ockendon, "Modeling mushy region," Appl. Sci. Res., vol. 44, pp. 1-7, 1987.

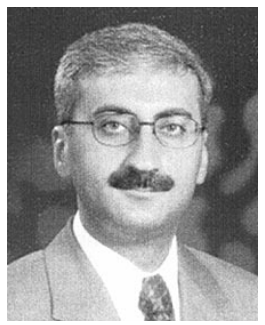

Esam Alawadhi received the M.S. degree from the University of Pittsburgh, Pittsburgh, PA, in 1998 and the Ph.D. degree in mechanical engineering from Carnegie Mellon University, Pittsburgh, PA, in 2001

$\mathrm{He}$ is an Assistant Professor of mechanical engineering at Kuwait University. His research focuses on thermal management of electronics devices, and modeling melting and solidification processes.

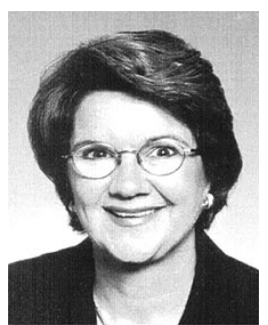

Cristina Amon (F’02) received the Mech.Eng. degree from Simon Bolivar University, Venezuela, in 1981, and the M.S. and Ph.D. degrees in mechanical engineering from the Massachusetts Institute of Technology, Cambridge, in 1985 and 1988, respectively.

She is a Professor in the Department of Mechanical Engineering and holds a joint appointment in biomedical engineering. She joined Carnegie Mellon University, Pittsburgh, PA, in 1988 where she is currently the Raymond J. Lane Distinguished Professor of Mechanical Engineering and Director of the Institute for Complex Engineered Systems (ICES), a strategic initiative of the College of Engineering for pursuing multidisciplinary research on complex systems. She has contributed six book chapters, one McGraw-Hill Custom Textbook, and over 140 refereed articles in education and research literature. Her research pioneered the development of computational fluid dynamics (CFD) for formulating and solving thermal design problems subject to multidisciplinary competing constraints. This led to her creation of a multistage concurrent thermal design methodology based on hierarchical model refinement, which combines CFD, nondeterministic experiments and Bayesian statistics. She has also made seminal contributions on self-sustained oscillatory flows and thermal management of electronics, elucidating flow destabilization mechanisms which induce heat transfer enhancement with chaotic mixing; quantifying conjugate time-dependent effects in electronic packages with multi length and time scales; and developing on-demand recuperative transient thermal management technologies for portable electronics.

Dr. Amon received the SWE Distinguished Engineering Educator award in 1999 and Professor of the Year award for 2000, the Gustus L. Larson Memorial Award for outstanding achievements in Mechanical Engineering from the American Society of Mechanical Engineers (ASME), and several awards from the American Society for Engineering Education (ASEE), including the George Westinghouse Award in 1997 and the Ralph Coats Roe Award in 2002, and the "Engineer of the Year" Award from the Pittsburgh Chapter of ASME. She is a Fellow of ASME. Active in professional societies, she currently serves as Chair of the ASME HTD K-16 Committee on Electronics Cooling, chair of the ASME HTD K-3 Honors and Awards Committee, and executive member of the ASME Electronic and Photonic Packaging Division. Her editorship roles include associate editor for the ASME Journal of Heat Transfer, the IEEE TRANSACTIONS ON COMPONENTS AND PACKAGING TECHNOLOGIES, Associate Editor for Electronic Packaging $G \& B$ Book Series, and co-editor of the Journal of Heat and Mass Transfer and ASME publications. She was elected General Chair of the ITherm 2002 Intersociety Conference on Thermal and Thermomechanical Phenomena in Electronic Systems. 